\title{
Análise morfoanatômica de folhas de Ocotea puberula (Rich.) Nees,
} Lauraceae

\author{
Paulo V. Farago ${ }^{1^{*}}$, Jane M. Budel ${ }^{2}$, Márcia R. Duarte', Tomoe Nakashima ${ }^{2}$ \\ ${ }^{1}$ Departamento de Ciências Farmacêuticas, Universidade Estadual de Ponta Grossa, Av. Carlos Cavalcanti 4748, \\ 84030-900, Ponta Grossa, PR, Brasil, \\ ${ }^{2}$ Programa de Pós-graduação em Ciências Farmacêuticas, Departamento de Farmácia, Universidade Federal do \\ Paraná, Av. Lothário Meissner 3400, 80210-170, Curitiba, PR, Brasil
}

\begin{abstract}
RESUMO: Ocotea puberula (Rich.) Nees é uma espécie arbórea nativa, que ocorre por toda a América tropical e subtropical, em quase todas as formações florestais. É conhecida como guaicá, canela-guaicá e canela-sebo, sendo utilizada por comunidades indígenas no tratamento de tumores e afecções da pele. Este trabalho analisou a morfoanatomia das folhas da espécie, a fim de fornecer subsídios anatômicos à sua identificação. O material botânico foi fixado e submetido a técnicas usuais de microscopia fotônica e eletrônica de varredura. As folhas são alternas, simples, inteiras, elípticas ou elíptico-lanceoladas e revolutas na base. A anatomia foliar revela a ocorrência de estômatos paracíticos e tricomas tectores unicelulares na face abaxial, mesofilo dorsiventral, nervura mediana biconvexa, com sistema vascular constituído de feixe único do tipo colateral em arco aberto. Na estrutura anatômica da folha, são observadas células secretoras de substâncias lipofílicas e mucilaginosas.
\end{abstract}

Unitermos: Ocotea puberula, Lauraceae, morfoanatomia.

\begin{abstract}
Leaf morpho-anatomical analysis of Ocotea puberula (Rich.) Nees, Lauraceae". Ocotea puberula (Rich.) Nees is a native woody species. It occurs all over tropical and subtropical America, in almost all the forest formations. It is known as guaicá, canela-guaicá and canelasebo, being used by indigenous communities to treat skin diseases and tumours. This work has analysed the leaf morpho-anatomy of the species, in order to supply anatomical information for its identification. The botanical material was fixed and prepared according to usual optical and scanning microtechniques. The leaves are alternate, simple, entire, elliptical or elliptical-lanceolate and revolute at the base. The leaf anatomy shows paracytic stomata and unicellular non-glandular trichomes on the abaxial surface, dorsiventral mesophyll and biconvex midrib consisting of a collateral bundle in open arc. Oil and mucilage cells are found in leaf anatomical structure.
\end{abstract}

Keywords: Ocotea puberula, Lauraceae, morpho-anatomy.

\section{INTRODUÇÃO}

A família Lauraceae A. L. Jussieu representa um dos mais importantes grupos da flora dendrológica brasileira, reunindo espécies de valor, tanto pela qualidade da madeira, como pela produção de frutos, óleos e especiarias (Marchiori, 1980). Os integrantes desse taxa compreendem árvores e arbustos (Cronquist, 1981), com exceção de Cassyta (Barroso, 1978), e se distribuem geograficamente nas regiões tropical e subtropical, principalmente da América do Sul (Vattimo, 1979).

O gênero Ocotea Aubl. engloba cerca de trezentas espécies (Rizzini, 1971), sendo que as representantes brasileiras de maior importância econômica são Ocotea porosa (Nees \& Mart.) Barroso (imbuia) e O. pretiosa Benth. \& Hook. f. (sassafrásbrasileiro) (Vattimo, 1980).

Diversas pesquisas têm sido conduzidas com diferentes espécies de Ocotea, visando o isolamento e a caracterização de compostos químicos. Dentre os metabólitos vegetais identificados, destacam-se os alcalóides benzilisoquinolínicos e aporfínicos (Vilegas et al., 1989; López et al., 1995; Dias et al., 2003), as lignanas (Morais et al., 1999) e neolignanas (Aiba et al., 1973; Romoff, et al., 1984; Dias et al., 1986; Felicio et al., 1986; Marques et al., 1992; Drewes et al., 1995; Lordello, 1996), os monoterpenos (Diaz et al., 1980), os sesquiterpenos (Aiba et al., 1973; Palomino; Mandonado, 1996) e os fenilpropanóides (Diaz et al., 1980).

Ocotea puberula (Rich.) Nees é uma espécie arbórea nativa, comum no planalto meridional, principalmente em florestas com Araucárias (Lorenzi, 1998). Trabalho etnobotânico efetuado em comunidades indígenas do Paraná e Santa Catarina (Marquesini, 1995) revelou o uso da casca do presente táxon no tratamento de tumores e afeç̧ões da pele. Agricultores familiares paranaenses vêm empregando o chá das folhas em diarréias e disenterias (Ebejer, 2001).

Em O. puberula, foram isolados quatro alcalóides aporfínicos, a ocoteína (Jacobucci, 1954), a deidroocoteína, a dideidroocoteína (Baralle et al., 1972) e a talicminina (Baralle et al., 1973). A análise por GC/MSMSD revelou a presença de espatulenol (15,73\%), 2- $\beta$ pineno $(9,70 \%)$, biciclogermacreno $(9,38 \%)$, germacreno 
D (6,62\%), $\alpha$-pineno (6,26\%), trans-muurolol (5,72\%), limoneno $(5,50 \%)$, nerolidol $(4,42 \%)$, calareno $(3,64 \%)$ e delta-cadineno (3,08\%), como sendo os principais componentes do óleo essencial extraído das cascas da espécie (Farago, 2002).

O presente trabalho tem por objetivo analisar a morfoanatomia foliar de Ocotea puberula (Rich.) Nees, Lauraceae, a fim de fornecer subsídios anatômicos à identificação da espécie.

\section{MATERIAL E MÉTODOS}

A coleta do material botânico foi realizada no Parque Municipal da Boca da Ronda, localizado próximo às coordenadas $50^{\circ} 27^{\prime}$ de longitude $\mathrm{W}$ e $25^{\circ} 08^{\prime}$ de latitude S, no perímetro urbano de Ponta Grossa - Paraná, em fevereiro de 2001. As exsicatas foram identificadas por taxonomista e encontram-se depositadas no Herbário do Departamento de Botânica do Setor de Ciências Biológicas da Universidade Federal do Paraná (UPCB), sob o número 43562.

A fixação das folhas adultas foi realizada no próprio local de coleta, utilizando-se FAA 70 (Johansen, 1940) e fixador de Karnovsky (1965), sendo posteriormente armazenadas em álcool etílico a $70^{\circ}$.

Para a preparação das lâminas permanentes, utilizou-se a técnica de inclusão em glicol metacrilato, de acordo com as indicações do fabricante (Polysciences ${ }^{\circledR}$ ) e segundo Feder e O’Brian (1968). As folhas, incluindo os pecíolos, sofreram seccionamento transversal e longitudinal em micrótomo rotatório Spencer 820, obtendo-se secções de 7 a $9 \mu \mathrm{m}$. Para a coloração, empregou-se solução de azul de toluidina a 0,05\% (Sakai, 1973). Como meio de montagem foi usado Entellan ${ }^{\circledR}$.

Para a avaliação histoquímica, foram obtidas secções transversais à mão livre da região mediana da folha de $O$. puberula, posteriormente tratadas com cloreto férrico (Johansen, 1940) para comprovação de compostos fenólicos. Os registros fotográficos foram realizados em Fotomicroscópio Zeiss MC-80. As escalas micrométricas foram fotografadas e ampliadas nas mesmas condições ópticas.

Para a análise ultra-estrutural da superfície foliar, de acordo com Souza (1998), as amostras foram fixadas em FAA 70, desidratadas em série etanólica crescente e pelo ponto crítico no equipamento Balzers CPD-010 e, após montagem em suporte metálico, submetidas à metalização com ouro em aparelho Balzers Sputtering SCD-030. As eletromicrografias foram realizadas em microscópio eletrônico de varredura Jeol JSM 6360 LV $(15 \mathrm{kV})$. O registro das imagens ocorreu pela utilização de software específico.

\section{RESULTADOS}

Ocotea puberula (Rich.) Nees, Lauraceae (Figs. 1 e 2), possui folhas alternas, simples, cartáceas, subcoriáceas ou coriáceas, elípticas ou elípticolanceoladas, base aguda e revoluta e ápice praticamente acuminado, medindo comumente de 10-12 cm de comprimento por 3-4 cm de largura (Fig. 3), e tendo o pecíolo de 2-3 cm de comprimento.

Em vista frontal, a espécie revela epiderme com células apresentando paredes anticlinais poligonais na face adaxial (Fig. 4) e com leve sinuosidade na face abaxial (Fig. 5). A venação é reticulada em ambas as faces. As folhas são hipoestomáticas, com estômatos do tipo paracítico (Fig. 5). Em secção transversal, observase que os estômatos estão localizados no mesmo nível das demais células da epiderme.

Em secção transversal da lâmina foliar (Fig. 7), a epiderme apresenta-se uniestratificada em ambas as faces e revestida por espessa cutícula. Cera epicuticular, com aspecto de pequenas granulações está presente, bem como alguns tricomas tectores unicelulares (Fig. 6). O mesofilo é do tipo dorsiventral (heterogêneo assimétrico) composto por parênquima clorofiliano paliçádico uni ou biestratificado e parênquima clorofiliano esponjoso multiestratificado, variando de seis a dez estratos celulares. Distribuídos no mesofilo, também são observadas células secretoras de substâncias de natureza lipofílica e mucilaginosa (Fig. 7).

Em secção transversal, a nervura principal (Fig. 7) apresenta-se biconvexa, sendo mais proeminente junto à face abaxial. A epiderme é uniestratificada, com células que apresentam a parede periclinal externa de formato levemente lenticular em ambas as faces, e é revestida por cutícula relativamente espessada. Subjacentemente à epiderme, observam-se várias camadas de colênquima angular, de cerca de seis estratos junto à face adaxial e aproximadamente quatro estratos na face abaxial (Fig. 8).

O sistema vascular (Fig. 7) é constituído por um feixe único do tipo colateral em arco aberto, possuindo o xilema voltado para a face adaxial. Este apresenta os elementos traqueais enfileirados, separados por raios parenquimáticos. Entre o xilema e o floema distingue-se uma zona cambial e todo o feixe vascular é envolto por uma bainha esclerenquimática.

A presença de células contendo compostos fenólicos é evidenciada na nervura principal, utilizando o reagente cloreto férrico (Fig. 8).

Em secção transversal, o pecíolo (Fig. 9) revelase com formato plano-convexo. O sistema de revestimento é semelhante ao anterior. Em posição adjacente, encontrase uma faixa de colênquima do tipo angular. Mergulhado no parênquima fundamental, observa-se um feixe vascular único, com formato de arco aberto do tipo colateral. Uma bainha esclerenquimática em diferentes estágios de lignificação envolve o feixe vascular. Células secretoras com conteúdo lipofílico e mucilaginoso também são observadas no pecíolo. 


\section{DISCUSSÃO}

A pesquisa da estrutura e da ontogenia de oito gêneros e doze espécies de Lauraceae revelou que a maioria dos estômatos da família são paracíticos (Metcalfe, 1987). Fahn (1990) indicou que é comum na família Lauraceae a presença de tricomas simples, não achatados e unicelulares.

Um estudo conduzido por Santos e Oliveira (1988) descreveu o parênquima paliçádico de $O$. porosa como uni ou biestratificado. De acordo com os mesmos autores, quando ocorre o tipo biestratificado, trata-se de um estrato de clorênquima intermediário aos parênquimas paliçádico e esponjoso típicos, de modo coincidente à espécie em questão.

Células contendo óleos essenciais em Lauraceae têm sido descritas por diversos autores (Solereder, 1908; Esau, 1960; Metcalfe, 1987; Buvat, 1989; Toledo, 1996; Maranho, 1998; Toledo, 2000). De acordo com Solereder (1908), as células mucilaginosas ocorrem nas folhas dos gêneros Persea, Phoebe, Ocotea, Nectandra, Sassafras e Litsea. Metcalfe (1987) relata que é comum a presença de células secretoras de óleos ou de mucilagem em pelo menos vinte gêneros da família Lauraceae. Segundo esse mesmo autor, as células oleíferas são geralmente

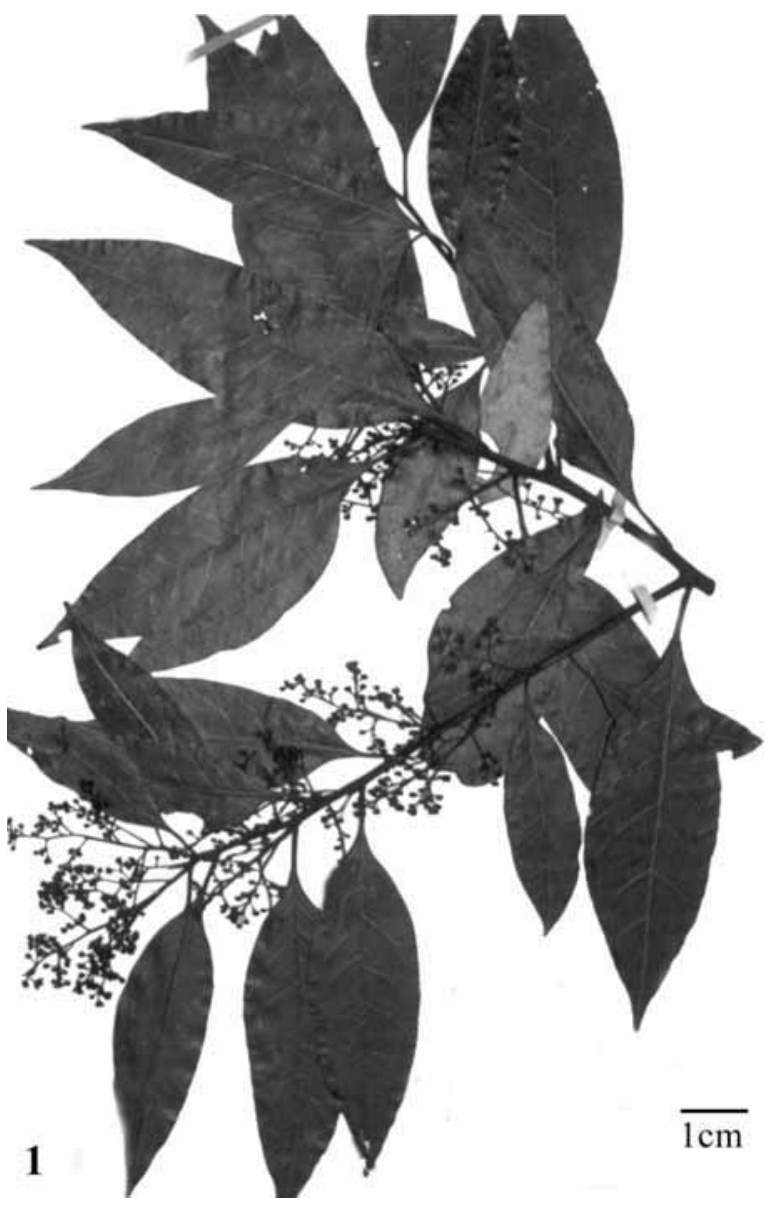

Figura 1. O. puberula - ramo da espécie, onde se observa a filotaxia e a inflorescência (crédito: I.J.M. Takeda). esféricas, com as paredes suberizadas e com conteúdo amarelado, e freqüentemente aparecem como pontos translúcidos nas folhas. As células mucilaginosas são semelhantes em tamanho, forma e distribuição às oleíferas, sendo encontradas em, pelo menos, quatorze gêneros. Em O. puberula, ambas estruturas secretoras foram evidenciadas, assemelhando-se morfologicamente aos relatos da literatura.

Os óleos essenciais e as mucilagens em Lauraceae encontram-se depositados em células secretoras que, em contraste com as estruturas multicelulares, são individuais, distinguindo-se das demais células pelo conteúdo, forma, tamanho e espessamento da parede (Santos; Oliveira, 1988; Fahn, 1990). Essas estruturas são consideradas homólogas, entretanto, alguns autores (Fahn, 1990; Bakker et al., 1992) sugerem que um tipo desenvolve-se a partir do outro. Bakker et al. (1992), por meio da reinvestigação estrutural, confirmaram que células de Cinnamomum contêm misturas lipofílicas e mucilaginosas, implicando um desencadeamento posterior em categorias distintas de células com óleo ou mucilagem.

Toledo (2000) descreve a presença de colênquima do tipo anelar na nervura principal de O. odorifera. $\mathrm{Na}$ face adaxial, o colênquima de $O$. odorifera é composto

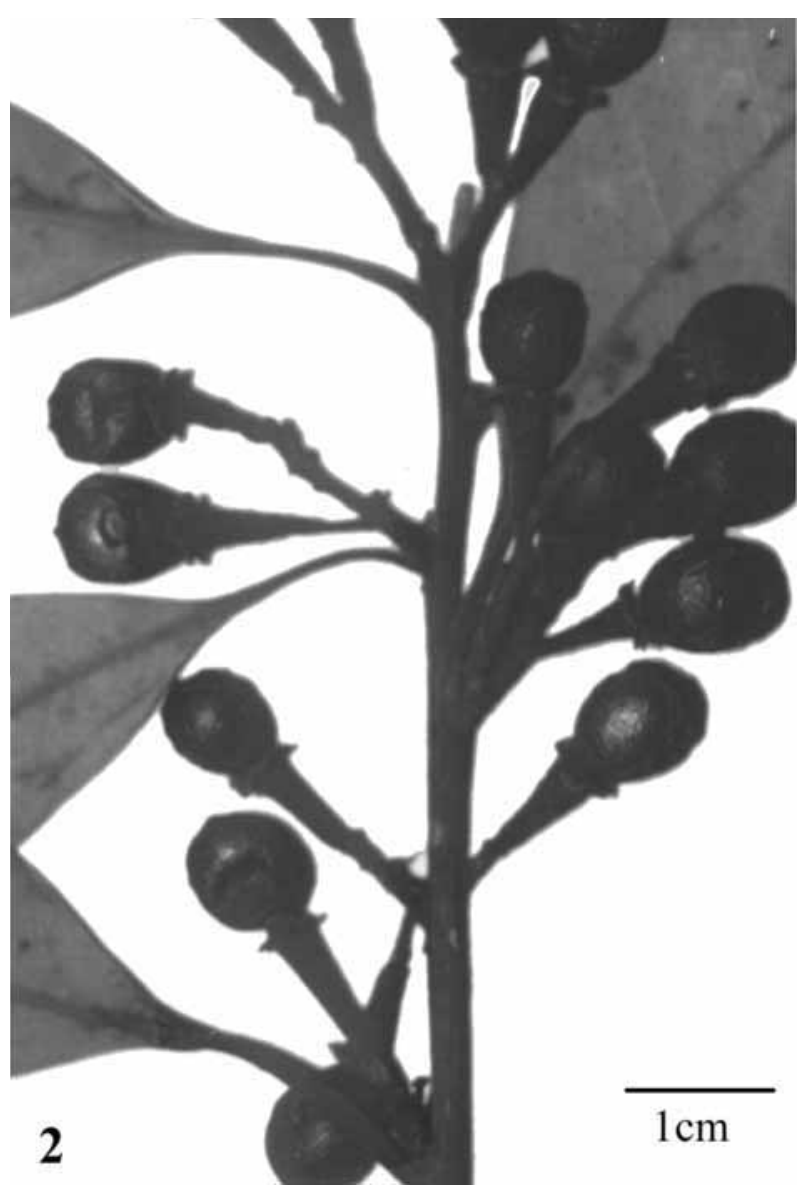

Figura 2. O. puberula - detalhe do ramo frutificado da planta (crédito: I.J.M. Takeda). 
por 3 ou 4 estratos de células, enquanto que, na face abaxial, o colênquima apresenta 2 ou 3 camadas de células. Diferentemente da espécie anterior, o colênquima de $O$. puberula foi classificado como angular.

\section{CONCLUSÃO}

Os caracteres morfoanatômicos da folha de O. puberula, considerados em conjunto, contribuem na identificação desta espécie medicinal, tais como: folha revoluta na base, hipoestomática, com tricomas tectores unicelulares na face abaxial, mesofilo dorsiventral, presença de células secretoras de substâncias lipofílicas e mucilaginosas, nervura mediana biconvexa, com sistema vascular do tipo colateral em arco aberto.

\section{AGRADECIMENTOS}

Os autores são gratos à taxonomista Dra. Inês Janete Matozzo Takeda, responsável pela identificação botânica, e ao Centro de Microscopia eletrônica da UFPR - Universidade Federal do Paraná.

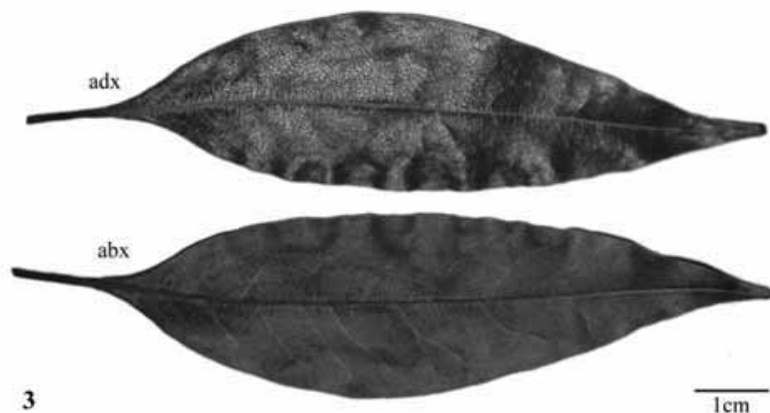

Figura 3. O. puberula - aspecto da folha, faces adaxial (adx) e abaxial (abx) (crédito: I.J.M. Takeda)

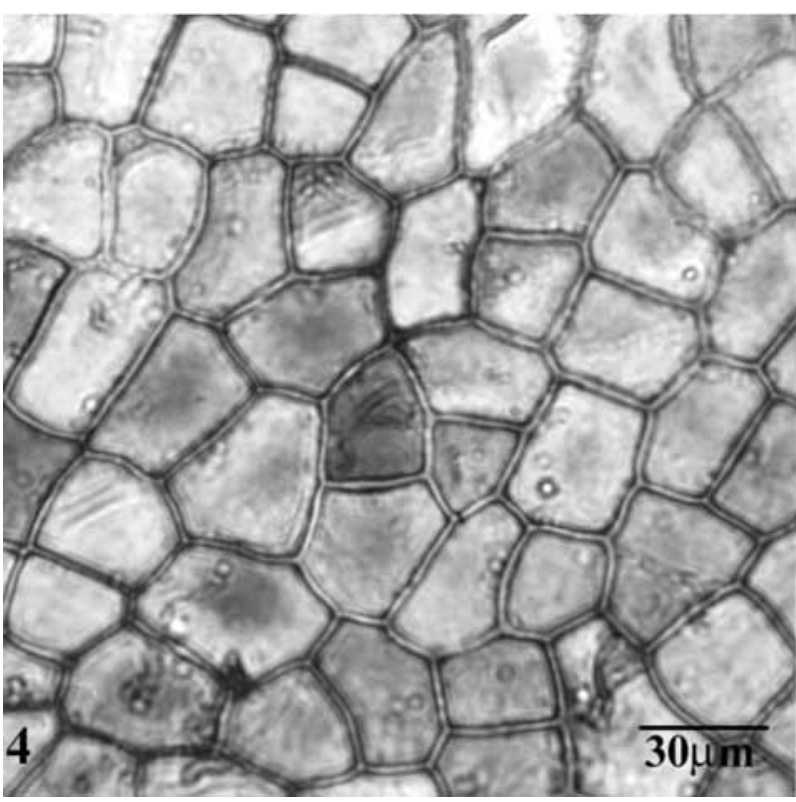

Figura 4. O. puberula - vista frontal da face adaxial da lâmina foliar, destacando o contorno poligonal das células.

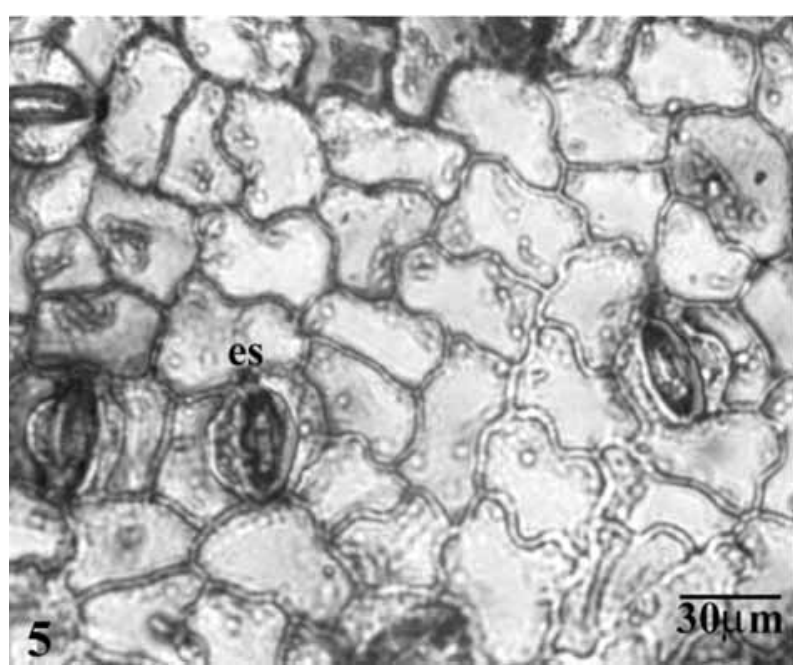

Figura 5. O. puberula - vista frontal da face abaxial da lâmina foliar, mostrando o contorno sinuoso das células e estômatos (es).

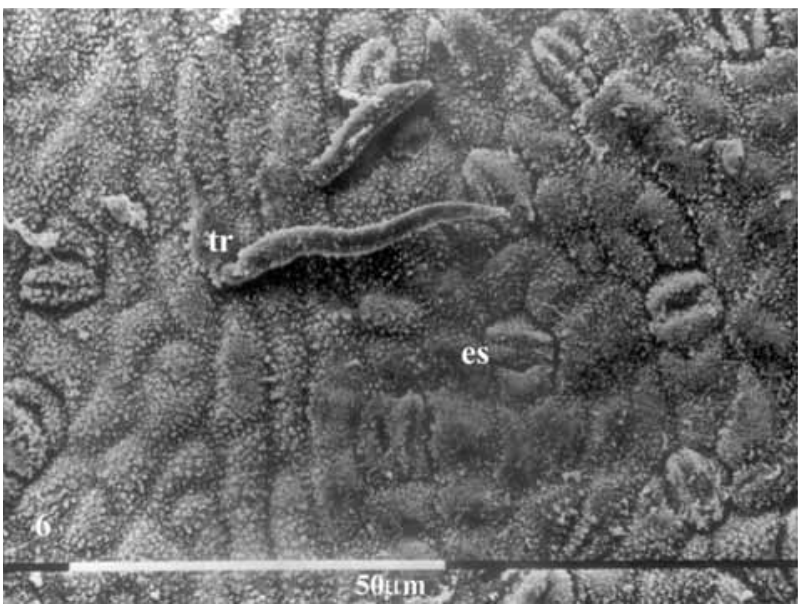

Figura 6. O. puberula - vista frontal da face abaxial da lâmina foliar, revelando tricomas tectores (tr), estômatos (es) e cera epicuticular (MEV 935x).

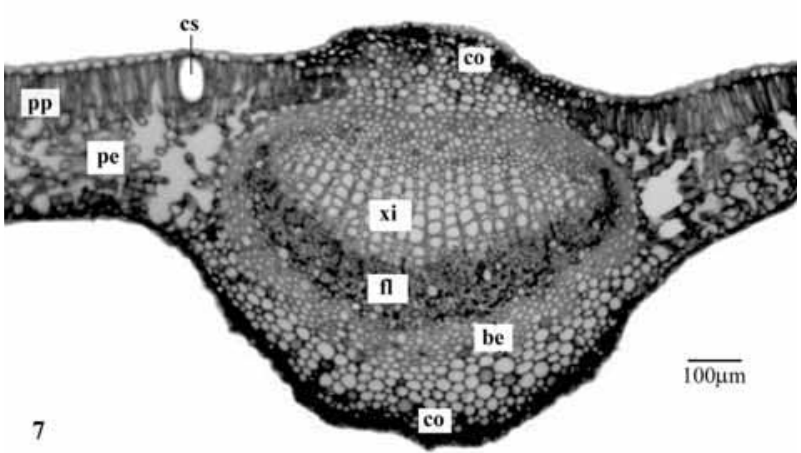

Figura 7. O. puberula - secção transversal da lâmina foliar e da nervura principal, indicando parênquima paliçádico (pp), parênquima esponjoso (pe), célula secretora de óleo essencial com formato elíptico (cs), colênquima (co), xilema (xi), floema (fl) e bainha esclerenquimática (be). 


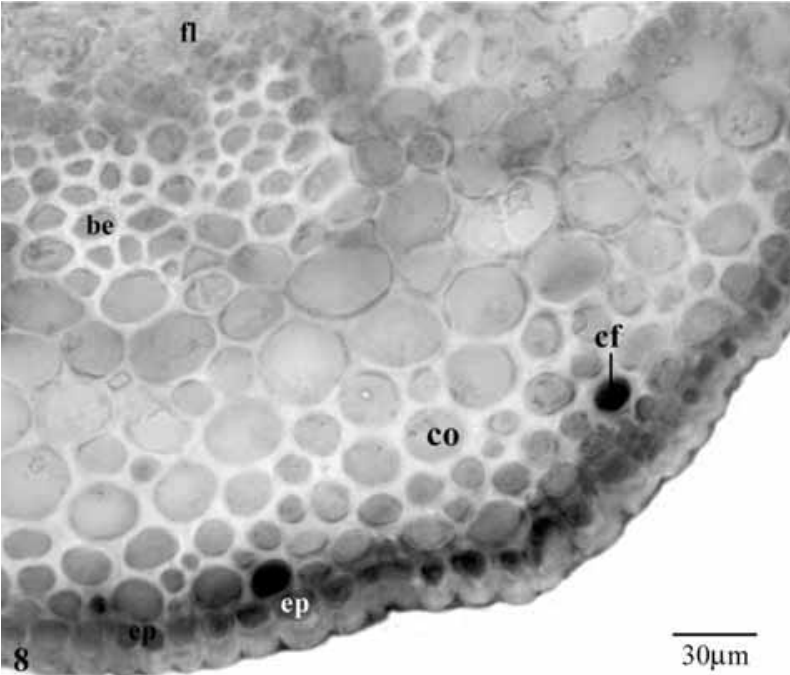

Figura 8. O. puberula - detalhe da nervura principal, junto à face abaxial, destacando epiderme (ep) revestida por cutícula espessada, célula contendo compostos fenólicos (cf), colênquima (co), bainha esclerenquimática (be) e floema (fl).

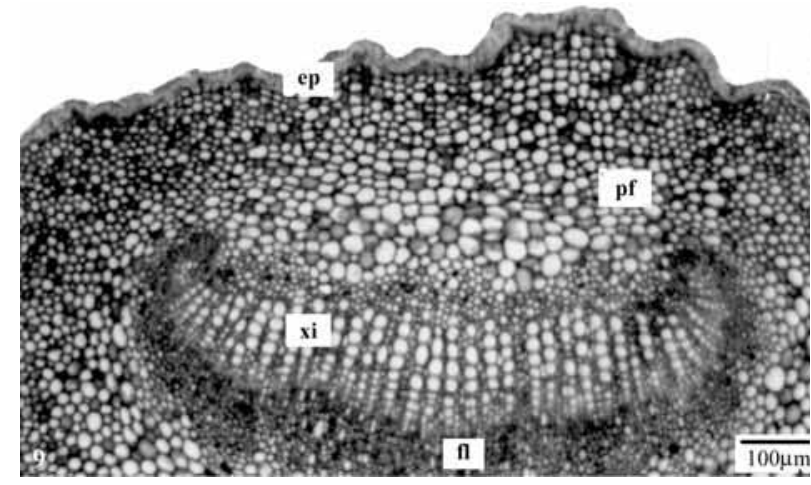

Figura 9. O. puberula - secção transversal do pecíolo, revelando epiderme (ep), parênquima fundamental (pf), xilema (xi) e floema (fl).

\section{REFERÊNCIAS}

Aiba CJ, Braz Filho R, Gottlieb OR 1973. Porosin: a neolignan from Ocotea porosa. Phytochemistry 12: 413-416.

Bakker ME, Gerritsen AF, Schaaf PJW 1992. Leaf anatomy of Cinnamomum Schaeffer (Lauraceae) with special reference to oil and mucilage cells. Blumea 37: 1-30.

Baralle F, Schvarzberg N, Vernengo M, Comin J 1972. Dehydroocoteine and didehydroocoteine from Ocotea puberula. Experientia 28: 875-876.

Baralle F, Schvarzberg N, Vernengo MJ, Moltrasio GY, Giacopello D 1973. Thalicminine from Ocotea puberula. Phytochemistry 12: 948-949.

Barroso GM 1978. Sistemática de angiospermas do Brasil. São Paulo: Livros Técnicos e Científicos, vol. 1.

Buvat R 1989. Ontogeny, cell differention and structure of vascular plants. New York: Springer-Verlag.

Cronquist A 1981. An integrated system of classification of flowering plants. New York: Columbia University, vol. 2.

Dias DA, Yoshida M, Gottlieb OR 1986. Further neolignans from Ocotea porosa. Phytochemistry 25: 2613-2616.

Dias CS, Silva IG, Cunha EVL, Silva MS, Braz-Filho R, Barbosa-Filho JM 2003. Isolamento e identificação de novos alcalóides de Ocotea duckei Vattimo (Lauraceae). Rev Bras Farmacogn 13: 62-63.

Diaz AMP, Gottlieb HE, Gottlieb OR 1980. Dehydrodieugenols from Ocotea cymbarum. Phytochemistry 19: 681682.

Drewes SE, Horn MM, Sehlapelo BM, Ramesar N, Field JS, Shaw S, Sandor, P 1995. Iso-ocobullenone and a neolignan ketone from Ocotea bullata bark. Phytochemistry 38: 1505-1508.

Ebejer WM 2001. A mesa de refeição é o altar da família. União da Vitória: Assessoria e Serviços a Projetos em Agricultura Alternativa.

Esau K 1960. Anatomia das plantas com sementes. São Paulo: Edgard Blücher.

Fahn A 1990. Plant anatomy. Oxford: Pergamon Press.

Farago PV 2002. Estudo morfo-anatômico e fitoquímico de Ocotea puberula (Rich.) Nees, família Lauraceae, da Região dos Campos Gerais, Ponta Grossa, Paraná. Curitiba, 80p. Dissertação de Mestrado - Universidade Federal do Paraná.

Feder N, O’Brian TP 1968. Plant microthecnique: some principles and new methods. Am J Bot 55: 123-142.

Felício JD, Motidome M, Yoshida M, Gottlieb OR 1986. Further neolignans from Ocotea aciphylla. Phytochemistry 25: $1707-1710$

Jacobucci GA 1954. Ocoteina, un alcaloide aislado de la corteza de Ocotea puberula (Rich.) Nees. Anal Asoc Quim Arg 42: 18-19.

Johansen DA 1940. Plant microtechnique. New York: Mc Graw Hill Book.

Karnovsky MJ 1965. A formaldehyde-glutaraldehyde fixative of high osmolarity for use in electron microscopy. $J$ Cell Biol 27: 137-138.

López JA, Barillas W, Gomez-Laurito J, Lin FT, Al-Rehaily AJ, Sharaf MHM, Schiff Jr PL 1995. Aporphine alkaloids of selected species of Nectandra and Ocotea. Planta Med 61: 589.

Lordello ALL 1996. Constituintes químicos de folhas e de cultura de células e tecidos de Ocotea catharinensis 
Mez (Lauraceae). São Paulo, 156p. Tese de Doutorado - Universidade de São Paulo.

Lorenzi H 1998. Árvores brasileiras: manual de identificação e cultivo de plantas arbóreas nativas do Brasil. Nova Odessa: Editora Plantarum, vol. 2.

Maranho LT 1998. Contribuição ao estudo botânico, fitoquímica, farmacológico e microbiológico de Persea major Kopp. (Lauraceae). Curitiba, 85p. Dissertação de Mestrado - Universidade Federal do Paraná.

Marchiori JNC 1980. Estudo anatômico do xilema secundário e da casca de algumas espécies dos gêneros Acacia e Mimosa, nativas no estado do Rio Grande do Sul. Curitiba, 86p. Dissertação de Mestrado - Universidade Federal do Paraná.

Marques MOM, Gomes MCCP, Yoshida M, Gottlieb OR 1992. Bicyclo[3.2.1]octanoid neolignans from Ocotea porosa. Phytochemistry 31: 275-277.

Marquesini NR 1995. Plantas usadas como medicinais pelos índios do Paraná e Santa Catarina, sul do Brasil - Guarani, Kaigang, Xogleng, Ava-Guarani, Krâo e Cayuá. Curitiba, 290p. Dissertação de Mestrado Universidade Federal do Paraná.

Metcalfe CR 1987. Anatomy of the dicotyledons: Magnoliales, Illiciales and Laurales. Oxford: Clarendon Press.

Morais LCSL, Almeida RN, Da-Cunha EVL, Da-Silva MS, Barbosa-Filho JM, Gray AI 1999. Further lignans from Ocotea duckei. Pharm Biol 37: 144-147.

Palomino E, Maldonado C 1996. Caparratriene, active sesquiterpene hydrocarbon from Ocotea caparripi. $J$ Nat Prod 59: 77-79.

Rizzini CT 1971. Árvores e madeiras úteis do Brasil: manual de dendrologia brasileira. São Paulo: Edgard Blücher.

Romoff P, Yoshida M, Gottlieb OR 1984. Neolignans from Ocotea acyphylla. Phytochemistry 23: 2101-2104.

Sakai WS 1973. Simple method for differential staining of paraffin embedded plant material using toluidine blue O. Stain Technol 43: 247-249.

Santos M, Oliveira PL 1988. Aspectos anatômicos da lâmina foliar de Ocotea porosa (Nees et Mart. ex Nees) J. Angely (Lauraceae). Ínsula 18: 3-22.

Solereder H 1908. Systematic anatomy of the dicotyledons: a handbook for laboratories of pure and applied botany. Oxford: Clarendon Press, vol. 2.

Souza W (ed.) 1998. Técnicas básicas de microscopia eletrônica aplicadas às Ciências Biológicas. Rio de Janeiro: Sociedade Brasileira de Microscopia Eletrônica, p. $1-44$.

Toledo MGT 1996. Contribuição ao estudo da Aniba rosaeodora Ducke. Curitiba, 62p. Monografia de Especialização Universidade Federal do Paraná.

Toledo MGT 2000. Estudo botânico e fitoquímico de Ocotea odorifera (Vell.) Rohwer. (Lauraceae) da região metropolitana de Curitiba. Curitiba, 110p. Dissertação de Mestrado - Universidade Federal do Paraná.

Vattimo I 1979. Flora ilustrada catarinense: Lauráceas. Itajaí: Herbário Barbosa Rodrigues.

Vattimo I 1980. Contribuição ao conhecimento da distribuição geográfica das Lauraceae VII. Rodriguésia 32: 351367.

Vilegas JHY, Gottlieb OR, Kaplan MAC, Gottlieb HE 1989. Aporphine alkaloids from Ocotea caesia. Phytochemistry 28: 3577-3578. 